\title{
Interests of Residual Renal Function in Peritoneal Dialysis
}

Narjes Ben Aicha*, Sanda Mrabet, Yosra Guedri, Wissal Sahtout, Awatef Azzabi, Salma Toumi, Dorsaf Zellama and Abdllatif Achour

Department of Nephrology Dialysis and Renal Transplantation, Sahloul Hospital, France

*Corresponding author: Narjes Ben Aicha, Department of Dialysis and Renal Transplantation, Sahloul Sospital, France, Tel: 412-689-4446; E-mail: narjesbenaicha@hotmail.fr

Received Date: April 03, 2017; Accepted Date: April 10, 2017; Published Date: April 17, 2017

Copyright: (C) 2017 Aicha NB, et al. This is an open-access article distributed under the terms of the Creative Commons Attribution License, which permits unrestricted use, distribution, and reproduction in any medium, provided the original author and source are credited.

\section{Abstract}

Background: Decline of Residual renal function (RRF) is commonly observed in dialysis patients. RRF may play a significant role in the treatment adequacy and outcomes of dialysis patients. Several prospective observational and interventional studies have shown that the presence of RRF was associated with an improved outcome and a reduced mortality in dialysis patients. Preserving RRF is an old holistic dream that still remains to date a source of debate among the nephrologists. (PD).

The aim of our study was to evaluate the impact of preservation of residual renal function in peritoneal dialysis

Methods: The study was retrospective, descriptive and analytical including patients on peritoneal dialysis in the Nephrology Department of Sahloul Hospital in Sousse during the period from 1 December 2006 to 30 June 2014.

We noted clinical and biological parameters for patients with and without RRF. The FRR was defined as a residual clearance upper than $1 \mathrm{ml} / \mathrm{min}$.

All statistical analysis was performed with SPSS statistical software version 20. For each parameter the mean \pm deviation was calculated. The significance of effects was tested using analysis of variance (ANOVA). Values $<0.05$ were considered significant. Multiple regression analysis was performed in order to investigate the relationship between RRF and various independent variables (age, gender, blood pressure, and etiology of end stage renal disease).

Results: During the study period, 48 patients were collected. RRF was found in $71 \%$ of patients with PD. Several benefits were demonstrated: better control of anemia $(9.2 \mathrm{vs} .8 .01 \mathrm{~g} / \mathrm{dl}$ ), better balance of uricemia (303 vs. 393 $\mu \mathrm{mol} / \mathrm{l})$ a better balance of phosphorus (1.4 vs. $1.8 \mathrm{mmol} / \mathrm{l})$ and a lower risk of peritonitis (absence of peritonitis in 71 vs. $30 \%)$.

Conclusion: The FRR is an important parameter that should be taken into account in our medical care in dialysis. Its protection should therefore be considered and it responds to many factors.

Keywords: End stage renal disease; Peritoneal dialysis; Residual renal function; Residual dieresis

\section{Abbreviations}

RRF: Residual Renal Function; ESRD: End Stage Renal Disease; PD: Peritoneal Dialysis; RRT: Renal Replacement Therapy; HD: Hemodialysis; CKD: Chronic Kidney Disease; GFR: Glomerular Filtration Rate; CAPD: Continous Ambulatory Peritoneal Dialysis; APD: Automated Peritoneal Dialysis; Hb: Hemoglobin; KDOQI: Kidney Disease Outcomes Quality Initiative

\section{Introduction}

End-stage renal failure (ESRF) is a medical and a public health problem in the world due to the increased incidence and due to the high cost of the renal replacement therapy (RRT). More than one million people survive through dialysis in the world [1]. In Tunisia, the number of patients requiring dialysis increases each year about 500 patients.

Over time in dialysis, the residual renal function (RRF) which represents the specific function of the native kidneys in patients on peritoneal dialysis (PD) or hemodialysis (HD) gradually decreases.

Decline of RRF is commonly observed in dialysis patients. It is an unavoidable phenomenon caused by the degenerative and fibrosis process of chronic kidney disease (CKD). However, the rate of RRF loss is not homogeneous among patients and may be affected by other factors such as treatment modalities and practice patterns [2].

RRF may play a significant role in the treatment adequacy and outcomes of dialysis patients. Several prospective observational and interventional studies have shown that the presence of RRF was associated with an improved outcome and a reduced mortality in dialysis patients $[3,4]$. Preserving RRF is an old holistic dream that still remains to date a source of debate among the nephrologists. 
The best clearance measure is still uncertain and different approaches have been used. Renal creatinine clearance is most frequently used, but it overestimates Glomerular Filtration (GFR) and has errors of accuracy related to urine collection.

Alternatively, the average of renal creatinine and urea clearances balances the overestimation of GFR by creatinine clearance with the underestimation by urea clearance. The presence of residual diuresis is required for RRF to exist. However, there may be discrepancies between the amount of residual diuresis and the residual GFR.

The method of RRF measurement is the eGFR, as recommended by the European Best Practice Guidelines. The eGFR can be calculated by taking the average of the urea and creatinine clearance (GFR = [Creatinine + urea]/2).

The aim of our study was to evaluate the impact of preservation of residual renal function in peritoneal dialysis.

\section{Methods}

\section{Type of the study}

The study was retrospective, descriptive and analytical.

\section{Study population}

These were patients on peritoneal dialysis in the Nephrology Department of Sahloul Hospital in Sousse during the period from 1 December 2006 to 30 June 2014

\section{Inclusion criteria}

We included adult patients, at least 18 years old, achieved at least 3 months of follow up. Whose were still dialyzed in the center at the time of data collection?

\section{Exclusion criteria}

We excluded patients whose had beneficed successively two modalities of treatment (DP and HD).

\section{Procedure for collecting data}

The data were collected on a pre-established form containing the following information:

Age, sex, type of nephropathy, comorbidity (high blood pressure, diabetes and heart disease).

Dialysis parameters: Dialysis duration in months, type of PD (continuous ambulatory peritoneal dialysis (CAPD) or automated peritoneal dialysis (APD)).

Clinical parameters: The overload and dehydration episodes, episodes of peritonitis.

We have defined 2 times: T0: start of PD and T1: data collection.

At these two times, we noted the following biological parameters: The levels of hemoglobin $(\mathrm{Hb})$, nutritional status, GFR, peritoneal clearance, Residual Diuresis, net peritoneal ultrafiltration, calcium, phosphorus, potassium, alkaline reserve, uric acid, the Kt/V.

Oligoanuri was defined as urine output of $<250 \mathrm{~mL} / 24$ hours.

The FRR was defined as a residual clearance upper than $1 \mathrm{ml} / \mathrm{min}$.
Baseline characteristics were compared between the two groups (Group 1: with RRF and Group 2: without RRF) by using chi-square tests.

All statistical analysis was performed with SPSS statistical software version 20 . For each parameter the mean \pm deviation was calculated. The significance of effects was tested using analysis of variance (ANOVA). Values $<0.05$ were considered significant. Multiple regression analysis was performed in order to investigate the relationship between RRF and various independent variables (age, gender, blood pressure, and etiology of ESRD).

\section{Results}

During the study period, 48 patients were collected. Of these 35 (71\%) retained a $\mathrm{RRF}$ at $\mathrm{T} 1$.

Table 1 shows the demographic characteristics of the two groups (with and without RRF).

\begin{tabular}{|l|l|l|}
\hline & RRF>1 ml/min & RRF<1 ml/min \\
\hline Number of patients & 35 & 13 \\
\hline Age (years) & $42[20-85]$ & $42[18-72]$ \\
\hline Sex (M/F) & $24 / 11$ & $9 / 5$ \\
\hline High blood pressure & $24(68 \%)$ & $8(61 \%)$ \\
\hline diabetes & $8(22 \%)$ & $4(30 \%)$ \\
\hline Duration of PD (months) & $26[3-77]$ & $41[9-104]$ \\
\hline APD & $12(34 \%)$ & $4(31 \%)$ \\
\hline CAPD & $23(65 \%)$ & $9(69 \%)$ \\
\hline $\begin{array}{l}\text { APD: Automated Peritoneal Dialysis; CAPD: Continuous } \\
\text { Dialysis }\end{array}$ & Ambulatory Peritoneal \\
\hline
\end{tabular}

Table 1: Demographic characteristics of patients with and without RRF in peritoneal dialysis.

Through an analytical study, we were able to identify the impact of RRF preservation on the clinical level (Table 2). Patients with RRF had fewer episodes of overload (fewer episodes of acute lung edema). They had fewer episodes of peritonitis; the Figures 1 and 2 shows the distribution of episodes of peritonitis between the two groups.

\begin{tabular}{|l|l|l|l|}
\hline & RRF>1 ml/min & RRF<1 ml/min & P \\
\hline $\begin{array}{l}\text { No episodes of } \\
\text { acute lung edema }\end{array}$ & $31(88.8 \%)$ & $10(76.9 \%)$ & 0.1 \\
\hline $\begin{array}{l}\text { No episodes of } \\
\text { edema of the } \\
\text { lower limbs }\end{array}$ & $22(62.8 \%)$ & $4(30 \%)$ & 0.03 \\
\hline $\begin{array}{l}\text { Systolic blood } \\
\text { pressure (mmHg) }\end{array}$ & 136 & 128 & 0.2 \\
\hline $\begin{array}{l}\text { Diastolic blood } \\
\text { pressure (mmHg) }\end{array}$ & 75 & 69 & 0.2 \\
\hline
\end{tabular}


Page 3 of 6

\section{No episodes of $25(71 \%)$} péritonitis

Table 2: Comparison of clinical characteristics of groups with and without RRF.

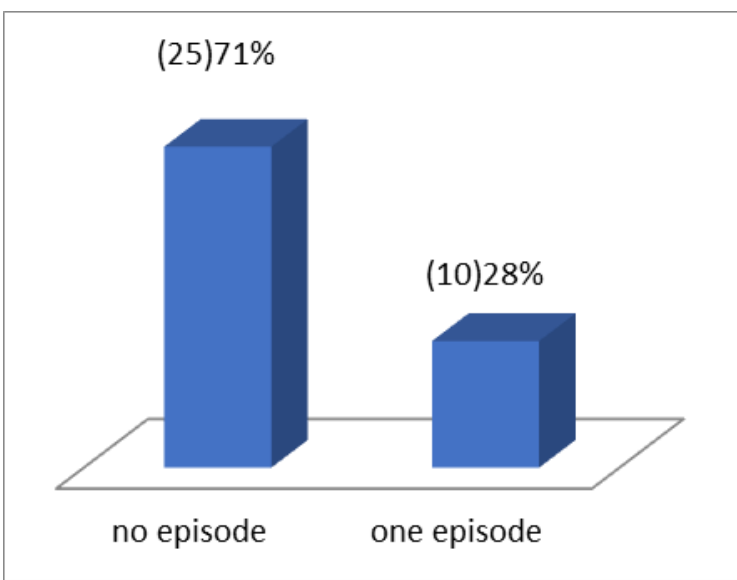

Figure 1: Number of episodes of peritonitis in patients with RRF $>1$ $\mathrm{ml} / \mathrm{min}$.

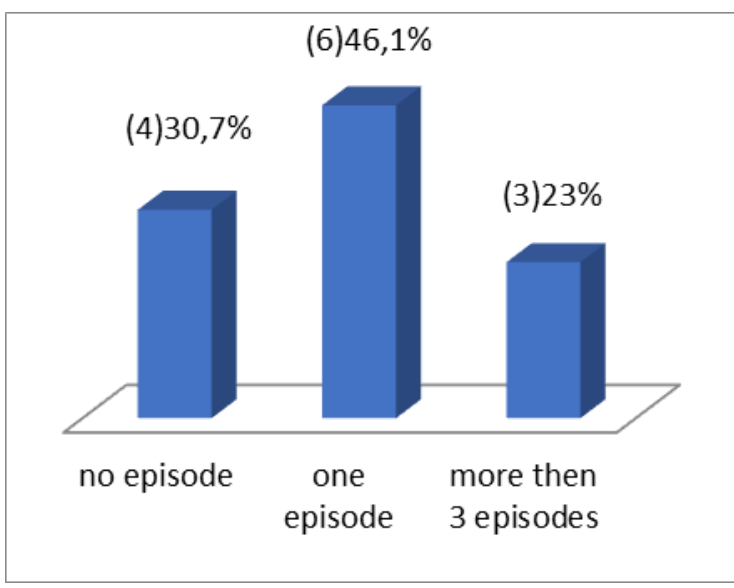

Figure 2: Number of episodes of peritonitis in patients with $\mathrm{RRF}<1$ $\mathrm{ml} / \mathrm{min}$.

Table 3 compares the dialysis parameters of groups 1 and 2. For both groups of patients, the RRF decreased progressively between T0 and T1. This decrease was greater for group 2. Over time between T0 and $\mathrm{T} 1$, there was a decrease in UF for both groups of patients and a comparable level of UF between the 2 groups.

At T1, all patients in the first group had Kt/V $>1.7$ and $70.5 \%$ of patients in group 2 had $\mathrm{Kt} / \mathrm{V}>1.7$. Kt/V means were comparable in both groups at both times $(\mathrm{P}=0.5)$.

For both groups 1 and 2, there was a decrease in total clearance over time. The decrease in total clearance was significant for group 2 $(\mathrm{p}=0.02)$.
At $\mathrm{T} 1$, the mean total clearance was significantly higher for group 1 $(\mathrm{p}=0.04)$. At $\mathrm{T} 1,85.3 \%$ of patients in group 1 had a clearance $>501 /$ week and $76.9 \%$ of patients in the second group had a clearance $>50 \mathrm{l} /$ week.

\begin{tabular}{|l|l|l|l|l|}
\hline & & $\begin{array}{l}\text { RRF>1 } \\
\mathbf{m l} / \mathbf{m i n}\end{array}$ & $\begin{array}{l}\text { RRF<1 } \\
\mathbf{m l} / \mathbf{m i n}\end{array}$ & $\mathbf{p}$ \\
\hline \multirow{2}{*}{ Diuresis (ml/24 h) } & T0 & $2170 \pm 659$ & $1325 \pm 616$ & 0.001 \\
\cline { 2 - 5 } & T1 & $890 \pm 670$ & $430 \pm 280$ & 0.02 \\
\hline \multirow{2}{*}{ RRF (ml/min) } & T0 & $3.5 \pm 2.1$ & $1.9 \pm 2.9$ & 0.02 \\
\cline { 2 - 5 } & T1 & $3.2 \pm 3.2$ & $0.9 \pm 0.6$ & 0.01 \\
\hline \multirow{2}{*}{ Ultrafiltration (ml/24 h) } & T0 & 1673 & 1521 & 0.1 \\
\cline { 2 - 6 } & T1 & 1276 & 1167 & 0.2 \\
\hline \multirow{2}{*}{$\begin{array}{l}\text { Total clearance (I/24 } \\
\text { h) }\end{array}$} & T0 & 88.5 & 79.4 & 0.04 \\
\cline { 2 - 6 } & T1 & 81.1 & 65.7 & 0.02 \\
\hline \multirow{2}{*}{ Kt/v } & T0 & $2.6 \pm 0.8$ & $2.5 \pm 0.6$ & 0.5 \\
\cline { 2 - 6 } & T1 & $2.4 \pm 0.1$ & $2.2 \pm 0.4$ & 0.5 \\
\hline
\end{tabular}

Table 3: Dialysis parameters of the two groups ( $R R F<1 \mathrm{ml} / \mathrm{min}$ and $\mathrm{RRF}>1 \mathrm{ml} / \mathrm{min}$ ).

At T1, only $29 \%$ of patients were anemic in group 1, while in the second group, the proportion was $76 \%$.

At T1, Hemoglobin levels were significantly higher in group 1 $(\mathrm{p}=0.03)$, while it were close between the two groups at T10 (Table 4).

In group 1, there was a significant increase in hemoglobin level between T0 and T1 $(p=0.01)$ whereas a decrease in hemoglobin level between $\mathrm{T} 0$ and $\mathrm{T} 1$ in group 2 was noted.

At T1: $30 \%$ of patients in group 2 had hypocalcaemia whereas in the first group hypocalcaemia was found in $37 \%$ of patients.

Hyperphosphatemia was found in $52 \%$ of group 1 patients and $53 \%$ of group 2 patients. At T1, the phosphor level was significantly higher in group 2 (0.05), although there was no significant difference between the two groups at $\mathrm{T} 0(\mathrm{p}=0.1)$.

At T1, 51\% of Group 1 had hypoalbuminaemia whereas in the second group $84 \%$ had hypoalbuminemia.

At T1: - Patients in group 2 had significantly higher uric acid levels $(\mathrm{p}=0.01)$ whereas there was no difference between the two groups at T0.

Patients with FRR had a significantly higher rate of Urinary sodium and Urinary potassium than those without FRR.

\begin{tabular}{|l|l|l|l|l|}
\hline & & $\begin{array}{l}\text { RRF>1 } \\
\text { ml/min }\end{array}$ & $\begin{array}{l}\text { RRF<1 } \\
\mathbf{m l} / \mathbf{m i n}\end{array}$ & p \\
\hline \multirow{2}{*}{ Hemoglobin $(\mathrm{g} / \mathrm{dl})$} & T0 & $8.7 \pm 1.3$ & $8.8 \pm 1.3$ & 0.1 \\
\cline { 2 - 5 } & T1 & $9.2 \pm 1.9$ & $8.01 \pm 0.8$ & 0.03 \\
\hline \multirow{2}{*}{ Calcium (mmol/l) } & T0 & $2.1 \pm 0.2$ & $2.2 \pm 0.3$ & 0.3 \\
\cline { 2 - 5 } & T1 & $2.1 \pm 0.1$ & $2.12 \pm 0.4$ & 0.7 \\
\hline Phosphate $(\mathrm{mmol} / \mathrm{l})$ & T0 & $1.7 \pm 0.5$ & $1.6 \pm 0.4$ & 0.1 \\
\hline
\end{tabular}




\begin{tabular}{|c|c|c|c|c|}
\hline & T1 & $1.4 \pm 0.4$ & $1.8 \pm 0.51$ & 0.04 \\
\hline \multirow{2}{*}{$\mathrm{nPCR}$} & T0 & $1.07 \pm 0.34$ & $1.07 \pm 0.17$ & 0.9 \\
\hline & $\mathrm{T} 1$ & $0.95 \pm 0.27$ & $0.89 \pm 0.3$ & 0.7 \\
\hline \multirow{2}{*}{ Albumin $(g / l)$} & TO & $31.4 \pm 3.8$ & $30.5 \pm 5.5$ & 0.5 \\
\hline & $\mathrm{T} 1$ & $29.6 \pm 4.8$ & $27.7 \pm 3.8$ & 0.1 \\
\hline \multirow{2}{*}{$\begin{array}{l}\text { Serum potassium } \\
(\mathrm{mmol} / \mathrm{l})\end{array}$} & T0 & $4.3 \pm 0.8$ & $4.2 \pm 0.5$ & 0.1 \\
\hline & T1 & $4.6 \pm 0.9$ & $4.9 \pm 1.09$ & 0.4 \\
\hline \multirow{2}{*}{$\begin{array}{l}\text { Urinary potassium } \\
(\mathrm{mmol} / \mathrm{l})\end{array}$} & TO & $16 \pm 14$ & $11 \pm 12$ & 0.08 \\
\hline & $\mathrm{T} 1$ & $20 \pm 16$ & $9.9 \pm 8$ & 0.04 \\
\hline \multirow{2}{*}{$\begin{array}{l}\text { Urinary } \\
(\mathrm{mmol} / \mathrm{l})\end{array}$} & TO & $48 \pm 28$ & $62 \pm 35$ & 0.1 \\
\hline & $\mathrm{T} 1$ & $89 \pm 69$ & $38 \pm 65$ & 0.04 \\
\hline \multirow{2}{*}{ Uricemia $(\mu \mathrm{mol} / \mathrm{l})$} & TO & $398 \pm 117$ & $380 \pm 73$ & 0.1 \\
\hline & $\mathrm{T} 1$ & $303 \pm 57$ & $393 \pm 62$ & 0.01 \\
\hline
\end{tabular}

Table 4: Comparison of biological characteristics of groups 1 and 2.

Statistical analysis was used to determine the benefits of preservation RRF in PD:

A better fluid balance and fewer episodes of overload.

A better dialysis adequacy and a higher total clearance. A better balance of uric acid. Better phosphor balance, control of anemia, and less risk of peritonitis.

\section{Discussion}

\section{Residual renal function in relation to volume control}

Several studies $[5,6]$ confirmed the importance of total sodium and fluid removal in predicting survival of peritoneal dialysis patients. Indeed, peritoneal dialysis patients who had a history of volume overload were noted to have more severe cardiac hypertrophy and dilatation as well as worse systolic and diastolic function.

As RRF declines, salt and fluid restriction becomes an increasing burden, and in anuria, an intake of $9 \mathrm{~g}$ of sodium chloride needs $1 \mathrm{~L}$ of water to keep osmolarity unchanged.

This study has shown that residual renal function has been increasingly implicated to be important in maintaining fluid balance of dialysis patients, especially in patients on peritoneal dialysis. Greater extracellular fluid was observed in peritoneal dialysis patients with residual glomerular filtration rate below $1 \mathrm{ml} / \mathrm{min}$ than those with residual glomerular filtration rate above $1 \mathrm{ml} / \mathrm{min}$. That ongoing renal salt and water excretion protects against the development of hypervolaemia.

As shown by Constantijn et al. [2] extracellular volume control worsened with time on peritoneal dialysis as residual renal function declines, The extracellular volume was $11.0 \pm 3.2 \mathrm{l} / \mathrm{m}^{2}$ in patients with FRR less than $2 \mathrm{ml} / \mathrm{min}$ and $8.2 \pm 1.4 \mathrm{l} / \mathrm{m}^{2}$ in patients with FRR greater than $2 \mathrm{ml} / \mathrm{min}$ with a significant difference $(\mathrm{P}=0.001)$.

This function could be particularly important for patients on PD, where ultrafiltration is not always simple.
For its part, Cheng et al. [7] did not find any difference in the extracellular volume between the two groups.

\section{The impact of RRF on PD adequacy}

Residual renal function is obviously an important factor for dialysis patients. It helps to achieve and/or to maintain dialysis adequacy [8]. It may contribute an important component (native renal clearance) of the overall treatment efficacy delivered by the renal replacement therapy modality (dialysis clearance). Solute clearances ensured by the native kidney are qualitatively more significant than clearances delivered by renal replacement therapies.

In our series, patients with $\mathrm{Kt} / \mathrm{V}>1.7$ were significantly more frequent in group with $\mathrm{RRF}>1 \mathrm{ml} / \mathrm{min}$.

Both in our series and in the literature, total clearance was significantly better in patients with RRF. It was $81 \mathrm{l} /$ wk in the group maintaining RRF and 61 l/wk in the second group of our series.

On the other hand, our levels of total clearance are similar to those of the literature. In the series of Chung et al. [9] the mean total clearance of RRF patients was $95 \mathrm{l} / \mathrm{wk}$ compared to $65.4 \mathrm{l} / \mathrm{wk}$ in the second group with a significant difference. In the series of Marro'n et al. [10] the mean total clearance of patients with RRF was $109.22 \mathrm{l} / \mathrm{wk}$ compared to $65.88 \mathrm{l} / \mathrm{wk}$ in the second group with a significant difference.

\section{Better balance of uric acid}

There is an increasing body of evidence indicating that hyperuricaemia may have a role in the development of hypertension, kidney disease, cardiovascular events and mortality $[11,12]$. Uric acidinduced preglomerular arterial disease, renal inflammation and activation of RAS and COX-2 have been demonstrated as potential mechanisms by which uric acid acts on the progression of renal disease [13-15].

Since the kidney excretes approximately two-thirds of the uric acid produced daily, serum uric acid tends to rise in patients approaching ESRD.

Due to the progressive loss of glomerular filtration, ESRD patients have lower renal uric acid clearance and higher serum uric acid levels.

In JT Park et al. study, it was demonstrated the association between uric acid hyperuricemia and the decline of RRF [16]. This was confirmed for our patients with an average of $303 \mu \mathrm{mol} / \mathrm{l}$ in the RRF group and $393 \mu \mathrm{mol} / \mathrm{l}$ in the second group ( $\mathrm{p}=0.028$ ).

This difference is explained by the kidney elimination of uric acid in patients with RRF.

\section{Phosphorus control}

The kidney plays an important role in phosphorus excretion. As renal function declines, phosphorus homeostasis is maintained through a compensatory decrease in renal tubular reabsorption, mediated partly by the phosphaturic hormones PTH and FGF-23. Our data clearly show that the kidney remains important for phosphorus control after the initiation of maintenance dialysis.

Hyperphosphatemia is a well-known risk factor for all-cause and cardiovascular mortality in dialysis patients. It has been associated with secondary hyperparathyroidism, renal osteodystrophy, and with the development of vascular calcifications. 
Several studies have shown the role of RRF in the control of hyperphosphoemia in PD. Suggesting that a beneficial role of RRF on phosphate control may to a certain extent be explained by increased urinary removal. In the Wang AY study, one-third of the peritoneal dialysis patients with preserved residual renal function were found to be hyperphosphatemia versus nearly half of the anuric patients. Of more importance is the finding that the degree of residual glomerular filtration rate, despite average being below $2 \mathrm{ml} / \mathrm{min}$ per $1.73 \mathrm{~m}^{2}$, remained strongly associated with phosphorus control in peritoneal dialysis patients. Even though peritoneal dialysis clearance contributes significantly to the phosphorus control in peritoneal dialysis patients, this study clearly demonstrated the limitation of peritoneal dialysis alone in achieving adequate phosphorus control in anuric patients taking the Dialysis Outcome Quality Initiative (DOQI)-recommended dietary protein of at least $1 \mathrm{~g} / \mathrm{kg}$ per day. In the series of Han et al. [17] the level of phosphorus was $5.2 \mathrm{mg} / \mathrm{dl}(1.67 \mathrm{mmol} / \mathrm{l})$ in the group without FRR and $4.8 \mathrm{mg} / \mathrm{dl}(1.54 \mathrm{mmol} / \mathrm{l})$ in the second group [18]. In the study presented here patients with RRF had better phosphorus control with an average of $1.4 \mathrm{mmol} / \mathrm{l}$ versus $1.8 \mathrm{mmol} / \mathrm{l}$ in the second group.

\section{Control of anemia}

Anemia is one of the most frequent complications of ESRD and is mainly related to a decrease in the level of erythropoietin. It can lead to cardiovascular complications and alter the quality of life of dialysis patients. In fact, intense fatigue, disorders of concentration and lack of energy often accompany the daily life of patients suffering from anemia. It is therefore one of the most difficult complications to support. The correction of anemia in dialysis allows an improvement of the quality of life and a reduction of the cardiovascular complications.

Several studies have shown that there is a combination of RRF with better correction of anemia and reduced consumption of synthetic erythropoietin. The presence of intrinsic renal function may be at the origin of a higher formation of erythropoietin with better control of anemia.

In the Han et al. [17] the hemoglobin level was $11.3 \mathrm{~g} / \mathrm{dl}$ in the DP group maintaining a FRR and $10.5 \mathrm{~g} / \mathrm{dl}$ in the second group. This is comparable to that found in our series. Patients in the first group had better hemoglobin compared to the second group.

\section{Less risk of peritonitis}

Infectious peritonitis is the most frequent and severe complication in PD. It is a strong predictor of mortality in PD.

In this study, the number of peritonitis was more important in patients who lost the RRF. The majority of patients with RRF had no episodes of peritonitis (78\%) whereas only $30.7 \%$ of patients who had lost RRF had no episodes of peritonitis with a significant difference $(\mathrm{p}=0.03)$.

Several studies have investigated the potential association between RRF and the incidence of peritonitis during PD therapy. During an analysis on the global prognostic significance of RRF, the incidence of peritonitis in patients presenting a GFR $<1 \mathrm{ml} / \mathrm{min}$ at the start of follow-up was found to be three-fold greater than that of patients with GFR $>1 \mathrm{ml} / \mathrm{min}$. Han et al. showed that for every $1-\mathrm{mL} / \mathrm{min} / 1.73 \mathrm{~m}^{2}$ increase in GFR at the start of PD therapy, there was a $20 \%$ decrease in risk of peritonitis [9].
Fontan et al. [19] showed a $25 \%$ greater risk of peritonitis-related mortality for every $1 \mathrm{~mL} / \mathrm{min} /$ minute decrease in baseline residual GFR in a similar multivariate-adjusted analysis.

One hypothesis for this observation is that the presence of RKF may offer immunomodulatory effects that protect against the development of peritonitis and its associated morbidity and mortality. However, it also is likely that the association may be caused by the presence of the residual confounding effects of baseline comorbid conditions that may serve as risk factors for the development of future peritonitis episodes.

\section{Conclusion}

RRF facilitates the achievement of dialysis adequacy in end stage chronic kidney disease (CKD-5) patients. It facilitates patients' acceptance of renal replacement therapy (RRT) in minimizing dietary and fluid restriction. Maintenance of residual renal function proves to be an important objective in the care of our PD patients, with benefits for their survival, quality of life (reduced severity of fluid restriction), and risk of complications.

In this present study we have confirmed several benefits including control fluid balance, decrease risk of peritonitis, control of anemia, phosphor and uric acid. Given the important contribution of RRF to this benefit of PD patients, it is easy to assume that RRF may improve quality of life as perceived by PD patients. Hence the importance of the identification of factors that affect RRF. Several studies are interested in determining the factors influencing the RRF. The Kidney Disease Outcomes Quality Initiative (KDOQI) has published guidelines establishing several risk factors for a decline in GFR in patients with chronic kidney disease, such as age, race, blood pressure, and proteinuria.

\section{References}

1. Pouteil-Noble C, Villar E (2001) Epidemiology and etiology chronic renal insufficiency. Rev Prat 51: 365-371.

2. Konings CJ, Kooman JP, Schonck M, Struijk DG, Gladziwa U, et al. (2003) Fluid status in CAPD patients is related to peritoneal transport and residual renal function: evidence from a longitudinal study. Nephrol Dial Transplant 18: 797-803.

3. Rottembourg J, Issad B, Gallego JL, Degoulet P, Aime F, et al. (1983) Evolution of residual renal function in patients undergoing maintenance haemodialysis or continuous ambulatory peritoneal dialysis. Proc Eur Dial Transplant Assoc 19: 397-403.

4. Su-ah S, Young H, Sejoong K, Sung K, Jieun O, et al. (2011) Loss of residual renal function was not associated with glycemic control in patients on peritoneal dialysis. Perit Dial Int 31: 154-159.

5. Stegmayr BG (2003) Ultrafiltration and dry weight-what are the cardiovascular effects? Artif Organs 27: 227-229.

6. Katzarski k, Charra B, Luik A, Nisei J, Divino F, et al. (1999) Fluid state and blood pressure control in patients treated with long and short haemodialysis. Nephrol Dial Transplant 14: 369-375.

7. Cheng IT, Chen W, Tang W, Wang T (2006) Residual renal function and volume control in peritoneal dialysis patients. Nephron Clin Pract 104: 47-54.

8. Lameire $\mathrm{NH}$ (1997) The impact of residual renal function on the adequacy of peritoneal dialysis. Nephron 77: 13-28.

9. Chung SH, Heimbürger O, Stenvinkel P, Qureshi AR, Lindholm B (2003) Association between residual renal function, inflammation and patient survival in new peritoneal dialysis patients. Nephrol Dial Transplant 18: 590-597. 
Citation: Aicha NB, Mrabet S, Guedri Y, Sahtout W, Azzabi A, et al. (2017) Interests of Residual Renal Function in Peritoneal Dialysis. J Nephrol Ther 7: 291. doi:10.4172/2161-0959.1000291

Page 6 of 6

10. Marrón B, Remón C, Pérez-Fontán M, Quirós P, Ortíz A (2008) Benefits of preserving residual renal function in peritoneal dialysis. Kidney Int 73: 42-51.

11. Nakagawa T, Kang DH, Feig D, Sanchez-Lozada LG, Srinivas TR, et al (2006) Unearthing uric acid: An ancient factor with recently found significance in renal and cardiovascular disease. Kidney Int 69: 1722-1725.

12. Suliman ME, Johnson RJ, García-López E, Qureshi AR, Molinaei H, et al. (2006) J-shaped mortality relationship for uric acid in CKD. Am J Kidney Dis 48: 761-771.

13. Mazzali M, Kanellis J, Han L, Feng L, Xia YY, et al. (2002) Hyperuricemia induces a primary renal arteriolopathy in rats by a blood pressureindependent mechanism. Am J Physiol Renal Physiol 282: F991-F997.

14. Kanellis J, Watanabe S, Li JH, Kang DH, Li P, et al. (2003) Uric acid stimulates monocyte chemoattractant protein-1 production in vascular smooth muscle cells via mitogen-activated protein kinase and cyclooxygenase-2. Hypertension 41: 1287-1293.
15. Kang DH, Nakagawa T, Feng L, Watanabe S, Han L, et al. (2002) A role for uric acid in the progression of renal disease. J Am Soc Nephrol 13: 2888-2897.

16. Park JT, Kim DK, Chang TI, Kim HW, Chang JH, et al. (2009) Uric acid is associated with the rate of residual renal function decline in peritoneal dialysis patients. Nephrol Dial Transplant 24: 3520-3525.

17. Han SH, Sang C, Ea K, Jung K, Hyang S, et al. (2010) Reduced residual renal function is associated with endothelial dysfunction in patients receiving peritoneal dialysis. Perit Dial Int 32: 149-158.

18. Wang AY, Lai KN (2006) The importance of residual renal function in dialysis patients. Kidney Int 69: 1726-1732.

19. Fontan MP, Rodríguez-Carmona A, García-Naveiro R, Rosales M, Villaverde P, et al. (2005) Peritonitis-related mortality in patients undergoing chronic peritoneal dialysis. Perit Dial Int 25: 274-284. 